\title{
Strategies for Designing and Developing Services for Manufacturing Firms
}

\author{
A.R. $\operatorname{Tan}^{1}$, D. Matzen ${ }^{1}$, T. McAloone ${ }^{1}$ and S. Evans ${ }^{2}$ \\ ${ }^{1}$ Department of Management Engineering, Technical University of Denmark (DTU), Denmark \\ ${ }^{2}$ Manufacturing Department, Cranfield University, Cranfield, United Kingdom \\ at@mek.dtu.dk
}

\begin{abstract}
Product/service-systems (PSS) are in effect an approach to designing integrated products and services with a focus on both customer activities and product life cycle considerations. Literature offers a range of serviceoriented design strategies from product-oriented DfX approaches to more customer-oriented approaches such as integrated solutions and service design. These design strategies are mapped out in relation to how applicable they are to different types of services. Case studies from two industrial companies are used to confront the existing literature in order to begin to understand how manufacturing companies may align their business strategies with their product and service development activities.
\end{abstract}

\author{
Keywords: \\ Product/service-systems, Design for X, Product Life Cycle design, Service design
}

\section{INTRODUCTION}

Manufacturing companies have traditionally focused their efforts on designing, developing and producing physical products to offer on the market. Today global competition and demands for greater company responsibility of products throughout their entire life cycle are driving manufacturing companies to reorient business strategy from a product-orientation to service-orientation, where instead of the product itself, the activity and knowledge associated with the use of the product is perceived to be of more value to the customer. Value here is not considered to be embedded in the physical product but is rather created by supporting and enhancing the customer's utility of their products. Customers need not be concerned with the responsibility of learning how to use the product, maintain or dispose of it, but merely benefit from the effects of use. This is done through intangible services and knowledge intensification that ensure optimal operation and performance of products in relation to customer's needs.

A number of studies and research programmes [1] have focused on the economic potentials of these business strategies that aim to provide the utility of products throughout their life cycle by designing and delivering integrated solutions of products and services [2]. Several researchers believe that these approaches also have the potential to enable and motivate companies to reuse, rationalise and enhance their products and services more efficiently throughout their life phases, and thereby be more environmentally sustainable [3]. In the research community this approach has been given various names such as 'product-service systems (PSS)' [4], 'functional product development (FPD)' [5], 'service engineering' [6], 'servicization' [7], servitization [8], etc. Although the emphasis on sustainability varies, these terms are based on the same principle of service-orientation and are generally considered synonymous. In this paper the term 'product/service-systems (PSS)' is used.

In traditional manufacturing companies the physical product is considered to be at the core of the offering with services being complementary and supplemented in aftermarket activities. With PSS approaches this view changes. Here the customer's interaction with the product and its related activity is at the centre of attention. Value is created during the activity and based on the performance and outcome of the activity. This shift in view challenges our current understanding of development and the models used to represent the design and development task. At present little research has been done in the systematic design and development aspects of PSS [4]. This paper sets out to explore the implications of PSS approaches with regard to the way in which companies set up their design and development activities.

The aim of this paper is to provide an overview of the various design strategies that manufacturing firms may apply when developing integrated products and services that support customer activities.

\section{RESEARCH METHOD}

There is considerable literature in engineering design, product development and service marketing that deal with the design and development aspects of products and services. Extensive searches were performed in relevant journals and books within these fields and the literature on design strategies that relate to customer particular product life phases and the full range of services that manufacturing firms may offer to their customers was reviewed.

To compare and contrast the various findings in literature, case study evidence was gathered from two industrial companies. These empirical case studies have been compiled through two research projects with manufacturing firms each contributing with different aspects regarding the emerging service-orientation of their business. The first case study is from a company that amongst other things manufactures refrigeration controls and is based on interviews with the R\&D manager responsible for hardware design, interviews with a service technician and development manager of the service venture company, and analysis of internal documents regarding organisation, development management and component development project specifications. The second case study from an office furniture company is 
based on ethnographic participatory observation in a consultancy service development project over a period of 15 months. The project was based in the company's corporate research department, but was closely tied to international marketing, environmental issues and workspace strategy business consultants. Both companies are large global manufacturing firms with long manufacturing traditions and solid positions in their individual markets.

\section{LITERATURE REVIEW}

PSS are in effect an approach to designing integrated products and services with a dual focus on both product life cycle and customer activity considerations [9]. The literature reviewed provides examples of the span of design strategies that address this integration of products and services.

In the field of engineering design research a series of approaches dealing with specific design goals have been labelled 'Design for $X$ methodologies [10]. These methodologies, the most common being Design for Manufacturability, Design for Assembly, Design for Quality and Design for Cost, are applied during the design process to in order to achieve solutions with certain desired properties [11]. The ' $X$ ' in DfX may represent different life phase systems that are sought to be optimised (e.g. manufacturing, assembly, configuration, disassembly, etc.), or properties which the product is supposed to excel in during any of the life phase systems it encounters (e.g. cost, quality, reliability, flexibility, environment, etc.). The design of PSS demands simultaneous application of multiple DfX approaches even though they are partly in contradiction to one another [12].

In parallel to the very product-oriented engineering design approaches, service marketing literature provides insights to service design from a customer relationship perspective. The basic steps in the design methodologies (i.e. problem definition, idea generation, conceptual design, detail design, testing and implementation) proposed in service design literature are similar to product design, but tend to use customer activities as a reference instead of the physical artefact.

In the following an overview of the most relevant design methodologies related to the service aspects of products is provided. It is worthwhile noting here that the word 'service' has multiple meanings and therefore leads to some confusion in engineering design and manufacturing literature. Service may be understood as:

1. the activities relating to the maintenance and repair of products;

2. the performance or support of certain activities related to the transformation process of technical systems [11]; or as

3. the performance or support of certain responsibilities related to the customer activities.

The implications of implementing service-oriented design strategies in relating to knowledge, integration and the organisation are also elaborated upon.

\subsection{DfX approaches}

\section{Design for Maintainability/Serviceability}

These approaches cover the support of repair and maintenance activities of the product. Moss [13] defined design for maintainability as 'an element of product design concerned with assuring the ability of the product to perform satisfactorily can be sustained throughout its intended useful life span with minimum expenditure of money and effort'. The focus here is on the ease of repairing by considering repair properties during the design of the product. Design principles such as (design for) reliability, modularisation and good diagnostic systems are common practices. Tjiparuro and Thompson [14] suggest the most significant design axioms are: simplicity, part features, operating environment, part identification and assembly/disassembly principles. Modularisation is an example of where a design for assembly principle is a good match with maintainability.

To assure safety of operation and reliability of technical installations, a number of different analysis methods and tools exist, e.g. Failure mode and effects analysis (FMEA), Fault-Tree Analysis, etc. [15]. These analysis methods are well developed today and together with monitoring systems allow maintenance activities to be proactively employed to prevent unnecessary downtime and optimal performance [16].

The term maintainability and serviceability [15] seem to be almost synonymous, with possibly serviceability encompassing more design criteria in order to include delivery system aspects such as part availability and online or self diagnostic systems. General Motor design teams have used a Serviceability Task Evaluation Matrix (STEM) that includes criteria such as estimated repair and maintenance time, part cost, diagnosis time, tool requirements, technician training requirements and part availability [17].

Based on its Design for Manufacture and Assembly (DFMA) software, the consultancy firm Boothroyd Dewhurst Inc. [18], has also introduced a 'Design for Service' application. The application calculates a serviceability index based on Design for Assembly information and gives an estimate on service time and costs. A product's properties regarding its ease of taking apart and putting together again are of course also relevant properties for disassembly as well as recyclability.

Elaborating the aspects of full life cycle support, the design of maintainability also includes strategies regarding the planned service frequency and needed competence of technicians [19]. Takata et al. [20] present a framework for life cycle maintenance that includes the following activities:

1. Maintainability design

2. Maintenance strategy planning

3. Maintenance task control

4. Evaluation of maintenance results

5. Improvement of maintenance and products

6. Dismantling planning and execution

The key issues to be considered in this framework are:

- Adaptation to various changes during the life cycle

- Continuous improvement of products

- Integration of maintenance information

Although these issues are emphasised, no practical examples or systematic methodological approaches are offered on how this may be achieved in design. Nonetheless Design for Maintainability and Serviceability approaches represent the most basic first steps to PSS for a manufacturing company.

\section{Design for supportability}

Goffin [21] uses the term supportability to cover all product (after sales) supporting activities, covering both maintenance and repair, but also installation, training, spare parts and auxiliary products, documentation, availability, customer consultancy and warranty schemes. Compared to Design for Maintainability it seems the rationale for applying Design for Supportability methods are not just about cost reduction, but just as much about 
revenue generation. Goffin [21] lists several factors that typically prevent companies from developing products that are easy and efficient to support. These are:

- Support requirements are considered too late in the product development cycle.

- Field support engineers and managers, who know support problems first-hand, do not have the opportunity to influence product designs.

- Decisions taken to lower production costs may make support more difficult or expensive.

- Product features often take priority over product support considerations.

In the context of PSS where business strategies are focused on supporting product life and customer activities, the factors mentioned above should therefore be given higher priority and be central for the development team's objectives.

As Design for Supportability covers more activities than just repair and maintenance, so do the design criteria. These include focus on parameters such as reliability, availability, serviceability, usability and installability [21]. Design for supportability is an extension of Design for Maintainability/Serviceability with the potential of greater value to the customer. At the same time it requires more resources and competencies that a traditional manufacturer would not necessarily have at their disposal. Options are to build competence up and learn how to manage support activities over time or alternatively outsource support related activities to external partners.

\section{Design for Service}

Rolls Royce (power systems) is often cited as one of the companies that have made the transition from 'offering a Service around an existing Product' to 'designing a Service and the Product that supports it' [22]. Using the term 'Design for Service', Rolls Royce implemented a new development programme that strongly focused on life cycle costs that covered:

- Infrastructure \& Capability Investment e.g. design, manufacturing, assembly, test, overhaul, disposal, etc.

- Product Acquisition

e.g. research, development, manufacture, test, certification, marketing and sales, etc.

- Product Operation and Support e.g. line maintenance, consumables incl. fuel, disruption, overhaul refurbishment, regulatory support, etc.

- Product Disposal

e.g. resale, depreciation, physical disposal of parts at overhaul and whole engine at end of life

Customer requirements were decomposed to show drivers that maximised 'customer value of the service provided' and minimised 'the cost of providing the service' throughout the life cycle. In order to make this transition Harrison pointed out that it required a major change in both cultural paradigm and capability. Traditionally the designers and in-service support teams had each there own perspective on their task and responsibilities, but under the new paradigm they were required to work together towards a common goal. The capabilities required in this new approach emphasised:

- Translation of the cost of ownership targets into engineering and organisational deliverables.

- Effective service knowledge management.

- Life cycle cost analysis tools and skills.

- Effective maturity proving.
Design for service is an example of current state-of-the-art PSS design for manufacturing firms. Its approach is encompassing and requires a total restructuring of the development task and its subsystems [23]. The restructuring entails both the implementation of a new approach to product development as well as the challenge of a major organisational and cultural change within the firm.

\subsection{Service Design}

Service design as a field of research emerged in the 1980's [24] and is now an established discipline. Service design is characterised by the object of design being not a physical artefact, but rather a process or activity. The first considerations in service design came from researchers in marketing with a strong focus on customer relations.

Early research in the area focused on attempting to identify the different characteristics of products and services. The so-called IHIP (inseparability, heterogeneity, intangibility, and perishability) list was proposed as the key to viewing services as ontologically different from products. This simplified view has since been rejected, as the distinction between products and services is not so clear [25]. All products are delivered with services and all services contain physical products. This very customeroriented perspective is the primary concern in the area of relationship marketing [26]. In relationship marketing the product and service dichotomy is abandoned in favour of a customer value driven approach, focusing on delivery competences and resources. The focus is on identifying, establishing, maintaining and enhancing relationships to customers and stakeholders to ensure long-term profitability. Relationship approaches takes upon the perspective that it does not make sense to determine whether customers buy products or services, what they actually buy is the benefits that products and services provide them with. From this perspective all companies basically offer services, even manufacturing firms.

On an abstract level, a movement initiated by an article of Vargo and Lusch [27] has worked on a reconciliation of the several subdomains of marketing, and proposes a service dominant logic, not far from the principles of relationship marketing, as a fundamental approach to serving customers - regardless of the medium being physical products or intangible services. The principle behind PSS is a shift from a perception that value is mainly embedded in a physical artefact to a perception where the activities associated with the product are considered to be a better definition of value. PSS development therefore seems well aligned with the approaches of 'service dominant logic' and the domain of relationship marketing.

Vandermerwe [28] elaborates on how companies may focus on customer relationships through a methodology called 'customer activity cycles'. Its focus is on the activities that customers go through to get the benefits of the offered products and services. A customer activity cycle consists of three stages; pre - what goes on before the customer achieves the result; during - what happens while the customer derives the core benefit; and post what happens after the experience. Vandermerwe states that the customer activity cycle model can help to enable companies to identify offerings that it should strive to provide with value either directly or indirectly. A key concept here is the life time perspective, whether one thinks of it in terms of product life or in terms of the customer's activities. Life cycle thinking maps out the connections between the various activities that products and stakeholders play a part in. This perspective takes a broader, holistic and longer-term perspective, which often reveals the business potential of the whole value chain. It is only when a product interacts with a customer, or 
stakeholder, in an activity that one can actually determine the benefit, costs or even, the environmental effects.

Current state-of-the-art practices in service design involve [29]:

- customer involvement in the design process

- design of customer activities (e.g. service blueprinting)

- design of service providing system (e.g. service ecology, actor network)

- design of service touch points (e.g. the physical products and environment)

- service experiences

- experience prototyping, service scenarios (acting out services)

In service design the focus is on customer activities and one cannot always spot the physical product or it's relation to product development. Manufacturing firms already offer a variety of services in connection with their products but these are rarely reconsidered as a design object. When companies do re-design their current services it is often referred to as the development of new business models.

\section{Service Engineering}

In a series of articles a group of Japanese researchers [30] have proposed a conceptual framework, models and a design approach for what they call 'Service Engineering', i.e. they adopt an 'engineering' viewpoint on PSS design. The core model is the so-called service model. A service is an activity that entails a change of state of the service receiver. The receiver should probably be thought of as a metaphor, not (only) the person, but also what he/she does, when his/her activities change state. The service content is by nature material, energy and/or information, while the service channel can transfer, amplify and control the service content, and influence the state of the receiver indirectly.

\subsection{Knowledge in PSS design}

A prerequisite for PSS design is the ability to gather, store and analyse data about products and customers that then can provide information on how to enhance the value of customer activities. Today, manufacturing companies have two types of IT systems that attempt to cater for this, Product Lifecycle Management (PLM) and Customer Relationship Management (CRM) [31]. Each system has their own focus, PLM systems administer product specific data and information throughout its entire lifecycle, but as companies are rarely responsible for the use and disposal phases of their products, the gathering and processing of information here is rather poor. On the other hand CRM systems capture, store and analyse customer information and communication, but again not much information is obtained from the activities where the product is actually in use. From a product development point of view, a systematic gathering of information of product use would be extremely valuable to the development of new products and services. If a perpetual coupling of product and customer information during operation was possible, insights and knowledge could be gained to ensure that the customer's activities were continuously aligned with their customer's needs and behaviours. But for now the management, accessibility and relevance of knowledge to product development and designers is still not well established.

\subsection{Integration of design and development activities}

Traditionally in a manufacturing company, product development and marketing are seen as separate activities that are performed in different parts of the organisation. In order to improve the performance of product development many manufacturing companies have adopted systematic product development approaches that coordinate the development activities across the organisation. Here development projects are organised around multidisciplinary teams consisting of resources from product design and development, production and marketing. Under the terms concurrent engineering and integrated product development [32] models outlined each of the development phases and how they related to each other. This enabled people across the organisation to understand their roles and responsibility in development projects, so that these could be managed in a more efficient manner. Although integrated product development approaches have been widely adopted by industry, they have been criticised on various aspects, such as the risk of the development project being built on the wrong assumptions, limiting innovation and hindering the involvement of customers [33], besides the fact that they no longer represent appropriately how companies actually perform product development.

\subsection{Organisation of PSS design}

Today it is generally recognised that both development and marketing activities are not limited to specific organisational units but occur throughout the organisation [26]. Therefore, PSS design research like relationship marketing also incorporates the expansion, co-operation and integration of development activities, both internally in an organisation as well in development partnerships in value networks [34]. Davies et al. [2] has examined a handful of capital goods suppliers that have reorganised themselves to provide integrated solutions. The services provided by these firms span over systems integration, operational (i.e. operating, supporting, maintaining, and upgrading equipment), business consulting and financing. The manufacturing based firms had built up dedicated customer-oriented system integration organisations which are independent of their own product divisions. The inhouse product divisions are responsible for developing common technology and standardised product platforms, but the system integration units are not bound by them and may use external (and sometimes even competing) component suppliers.

\subsection{Overview of service-oriented development strategies}

Figure 1 attempts to illustrate the variety of design and development approaches found in literature that integrate products and services. Traditional engineering design is very much focused on the physical product. Operational services are the most product-oriented services. These services are best supported by Design for Serviceability methodologies which cater to design issues regarding maintenance and repair. The next level of design addresses the services that encompass the total product system and its full life cycle support. Design for Supportability seems to take these design issues into account. Still product-oriented but now using the customer's activities as the design object, Harrison's Design for Service approach [22] is an example of designing the service first with objectives clearly defined in terms of customer activity performance and not just the product's performance specifications. design of the physical product. Here it is rather the business strategy and supplier-customer relationship that is of importance. 


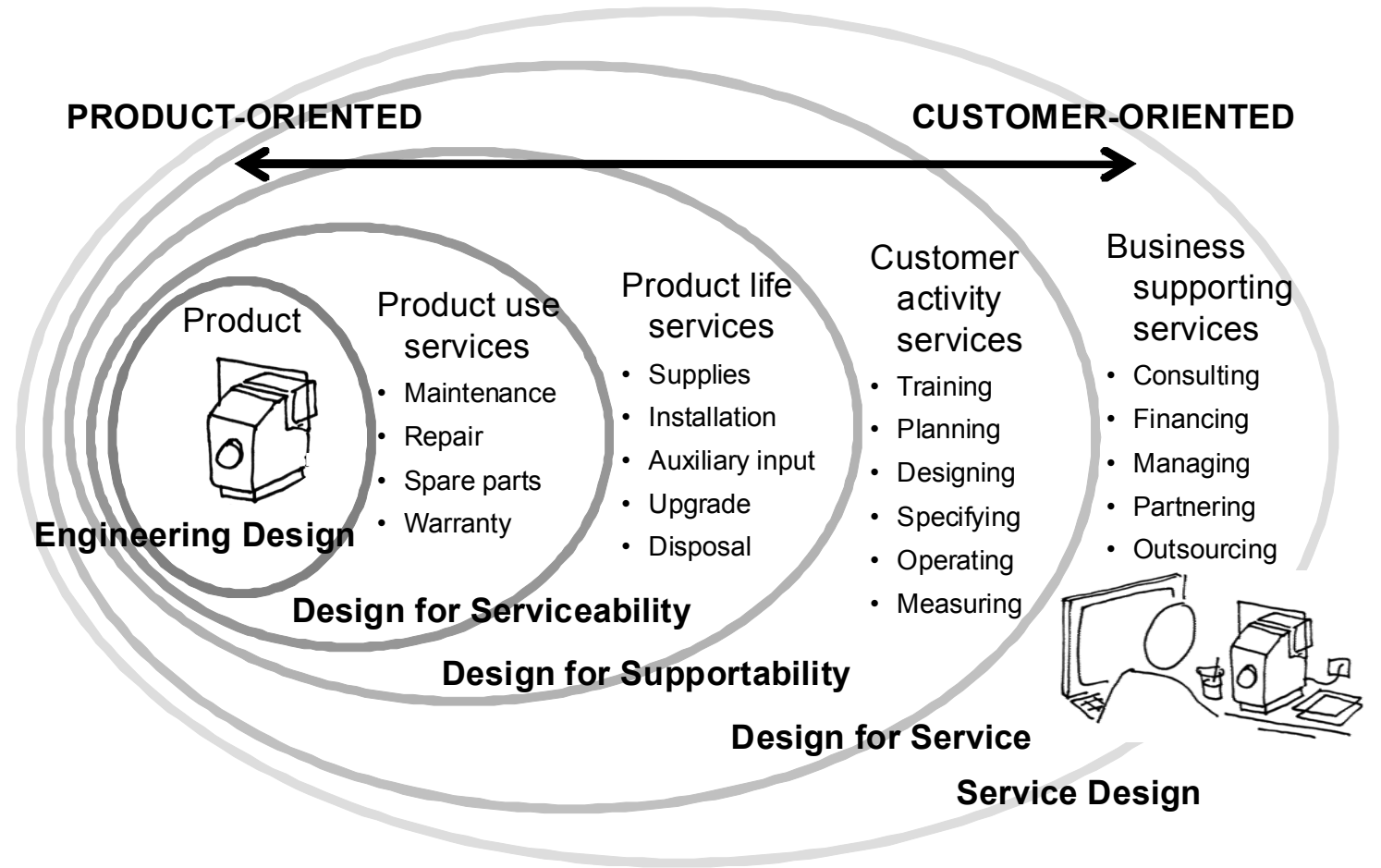

Figure 1: The span of service-oriented development methods offered by literature in relation to different types of services.

Although presented in rings, there is no sharp distinction between these types of services. The transition from product-orientation to customer-orientation is fluid. A manufacturing firm may offer these services in any constellation. The illustration merely provides an overview of which development strategy would be relevant to consider when designing these different types of service.

\section{CASE STUDIES OF SERVICE DEVELOPMENT STRATEGIES IN MANUFACTURING FIRMS}

To match up against the literature practical examples of how two different manufacturing companies approach services are introduced. The context of each case company is described in terms of their product development and customer relationship to understand their strategic approach to services.

\subsection{Danfoss A/S: From refrigeration controls to managing refrigeration}

The first case concentrates on the Refrigeration and AirConditioning business division of the Danish based company, Danfoss A/S. It describes an established PSS solution in a business-to-business (B2B) environment. The division develops and produces controls, valves compressors and other components for the refrigeration industry, traditionally as a subsupplier to OEM's of refrigerators and refrigeration contractors. In recent years Danfoss has entered the retail refrigeration (i.e. supermarket) market as a service provider. Through a subsidiary company, Danfoss now approaches supermarkets directly with a service offering branded Retail-Care $^{\mathrm{TM}}$. Danfoss refrigeration components and systems have the ability to communicate through electronic networks enabling monitoring, efficiency optimisation and fault detection from centralised monitoring sites. Utilising this technology, Danfoss offers refrigeration services to supermarkets on a global scale, promising optimised reliability and energy efficiency. They also offer consultancy on how to upgrade their customers' refrigeration system for preventive maintenance and performance optimisation.
Danfoss' objectives for Retail-Care ${ }^{\mathrm{TM}}$ are to move up the supply chain from a position as a component supplier and establish a closer link between the company and its endcustomers in the retail markets. This closer relationship increases Danfoss' knowledge of operational issues and positions them as providers of value added consultancy and service. Through Retail-Care ${ }^{\mathrm{TM}}$ Danfoss is involved with their retail customers from the design and specification of refrigeration components all the way to the operation, maintenance and management of the entire refrigeration system.

In the following sections some of the main drivers supporting Danfoss in their move into a service based business model are highlighted.

\section{Service-oriented development}

Food retail refrigeration systems are complex thermodynamic systems. Basically the system transports heat from various cold stores, cabinets and gondolas in the supermarket to a number of heat exchangers that emit the energy to the outside atmosphere. The different storage areas have individual temperature settings, power requirements and locations, while outside temperature and humidity vary daily due to weather and seasonal changes. The main design criteria for the system is to minimise the operational cost (power consumption and maintenance) while ensuring food is kept at the desired conditions so that food loss is minimised. This makes the initial setup and configuration, as well as regular inspection and adjustment of set points, a nontrivial task requiring a high level of technical competence. The first step towards an efficiently supportable design was the gradual technology shift from mechanical and thermostatic controls to electromechanical and digital control. The control of the technical system could then be centralised to a single computerised control unit enabling remote control of the complete store installation from a single (often software based) interface. As control loops were digitalised, more and more electronic sensors were fitted to the refrigeration systems, allowing real time operational data to be accessed. Finally as supermarket stores got 
connected to the internet it then became possible to monitor individual installation's operational data remotely enabling the transfer of remote control from the single store's control unit to centralised centres. Danfoss has invested substantially into data management systems research and fault detection and diagnosis (FDD) technology, and Danfoss can therefore now remotely access and diagnose the operation of their installations and propose adjustment and reconfiguration options to optimise energy efficiency.

\section{Redefining the customer relationship}

These technical capabilities allow Danfoss to offer a range of services from operation, maintenance and management of refrigeration systems to performance reporting and analysis to system optimisation and solution design and specification. Traditionally many food retailers did not understand or had the information of what their operation and management costs where or what savings could be achieved. Retail-Care ${ }^{\mathrm{TM}}$ gave Danfoss the opportunity to ensure that their products are correctly installed and operated so that they could actually deliver the performance level that they were originally designed to achieve. This has established Danfoss as a solution provider and not just a component supplier.

\section{Implications of the strategy for service development}

Traditionally Danfoss would sell its products to three major customer groups: OEM manufacturers of e.g. cabinets, gondolas, condensing units etc.; shop-fitters that dimension and install refrigeration systems in supermarkets, and wholesales companies that distributing components to maintenance and service companies and partly to the other two aforementioned customer groups.

With Retail-Care ${ }^{\mathrm{TM}}$ Danfoss had to integrate vertically in the value chain with OEMs, local entrepreneurial contractors and sometimes even competitors. It was crucial for Danfoss that their move up the value chain did not eliminate their traditional customers - other refrigeration OEM suppliers and contractors. These actors where still vital to in the business to ensure that Danfoss could provide local support globally - otherwise Danfoss would have to muster up considerable resources and capabilities to provide the service. Danfoss was careful to make sure they were still seen as an attractive partner for OEM suppliers and contractors when developing the Retail-Care ${ }^{\mathrm{TM}}$ services and therefore set up a separate 'solution venture organisation' outside of their existing components and systems business units. In this way, the component manufacturing business unit is not directly associated with the service operations of Retail-Care ${ }^{\mathrm{TM}}$, and the solution venture organisation does not directly interfere with the traditional business unit's existing customers. While this organisational construction leaves the traditional business model intact, the solution venture business can serve internally to inform research and product development of needs concerning service provision. They can also test and employ Danfoss' latest analysis software developments earlier than external customers due to the open knowledge exchange agreement between Danfoss' business units.

\subsection{Steelcase Inc.: From office furniture to workspace performance}

Our second case study in this paper is based on Steelcase, a global leader in office furniture based in Grand Rapids, Michigan. Steelcase's mission is 'to provide a better work experience' which they try to accomplish by offering a multitude of products and services that surround the office workplace environment. The company asserts that the physical office workspace environment is a strategic asset (on the same level that people, technology and business processes are) that can leverage their client's strategies and help them achieve their business goals. Steelcase positions itself as a company that understands and is knowledgeable about the way people work in offices as well as the social aspects of the activities associated with work. This allows them to assist their clients with knowledge and competencies to plan their workspace and ensure that it is aligned with the organisation's strategic objectives. However, Steelcase's research based knowledge of workspace design and how it supports strategic objectives is currently not always apparent to its clients.

\section{Service-oriented development}

Steelcase is usually associated with high quality products and is a leader in the implementation of Design for Environment methodologies when developing products. Products are designed to be durable, easy to assemble and disassemble and all material components are sought to be non-toxic and capable of recycling. These product properties tie in well with their furniture leasing, reparation, refurbishment and reselling services.

Based on customer demand Steelcase does offer a range of furniture management services, such as inventory management, reparation and refurbishment, asset management and move management, but the development of these services has been independent of the product development organisation.

The corporate portfolio has grown immensely and now includes subsidiaries that offer upholstery textiles and fabrics, lighting solutions, IT network cabling, visual communication products and even complete turnkey office buildings. This broad span of products and technologies allows Steelcase to design integrated space setting solutions that are dedicated to support specific work activities (e.g. individual concentrated work, confidential conversations, informal meetings, presentations, etc.). The competence to develop these solutions is further supported by the corporate research group, Workspace Futures (WSF). By investigating future trends for technology, space and social behaviour through rapid prototyping and user-centred observations WSF constantly provides ideas and concepts for new businesses, products and space setting solutions. Although the solutions from WSF are mostly productoriented they are typically designed to address a specific workspace issue or activity. This approach has proved effective when moving in to new markets such as health care and higher education environments.

The understanding of social behaviour in the workspace has also allowed Steelcase to form a team of high level business consultants that are well equipped with tools and competencies to assist clients to develop a workspace strategy that supports their organisation's objectives. These consultants operate out of the sales organisation but are typically engaged long before the choice of furniture supplier is made. They are capable of guiding clients through the whole process of workspace planning from understanding the current situation and its issues, defining the critical success factors of the workspace strategy in relation to the organisation's objectives, designing the workspace together with employees as well as performing post occupancy measurement. The consultants work and are paid fees independently of the furniture sales, but a majority of customers does tend to also choose Steelcase as their furniture provider if the consultants have been involved early in the process. WSF research work is currently oriented towards product and space applications. Although WSF has developed sales tools and services, this happens impromptu and does not follow the formalised and systematic approaches of their products. 


\section{Redefining the customer relationship}

Companies typically view office furniture and the physical work environment as necessities that represent costs. As an office furniture provider, Steelcase's main contact in the customer's organisation is the facility manager or purchasing department. The office furniture market is rather price sensitive so to avoid being caught in fierce price competition with low cost manufacturers they try to target higher level management in their customer's organisation by demonstrating how the physical workspace can be leveraged to improve business performance. Here they can have a different conversation with their clients. Instead of discussing the difference in price of furniture compared to competitors, they engage in discussions of how Steelcase can help employees be more productive or satisfied working. Architects and interior designers are an influential group of actors that Steelcase has to take in to consideration when dealing with customers. These actors are often responsible for the space planning and tend to be closer to higher level management in the customer's organisation. If this is the case Steelcase is careful not to take the lead in front of the customer but instead offer services that support the architect firm's work. How Steelcase works with their customer's is very dependent on who else is involved and when in the process do they get involved.

Implications of the strategy for service development

Although Steelcase offers a variety of service offerings such as financing, workspace planning, asset management, ergonomic training, reparations and refurbishment, move management, strategic workspace consulting, etc., manufacturing and the sale of furniture constitutes by far the majority of the company's activities. Steelcase has not formally defined a strong serviceoriented strategy, but it is aware that business will be difficult if it remains purely product-oriented. For now there is little integration of product and service development. Steelcase is however aware that often their products and space setting solutions once developed and installed at customers are not used as intended. A simple example of this is ergonomic features on chairs that are overlooked or misused and so their benefits fail to appear. The same applies for space settings that get under or over utilised. Steelcase realised that it is not enough to simply provide the physical products but has to instruct or encourage certain behaviours as well. This is an issue when launching new workspace concepts. If products or space settings are not adopted in the right way they will not live up to their true value potential and customers will not be satisfied. Product designers try to make things as intuitive and user-friendly as possible, but often the experience of products and settings are trivial if not enforced with training, workspace policies or services.

\section{CASE STUDY OBSERVATIONS AND DISCUSSION}

The two case studies show different approaches to developing services that can be offered with existing manufactured products. Both companies are clearly motivated by not wanting to be marginalised as pure product or component suppliers and seek opportunities where they can provide value-added knowledge and services. Danfoss' seems to have leveraged upon the development of their products' remote control functionalities that enable them to offer Retail-Care ${ }^{\mathrm{TM}}$ services, whilst Steelcase employs a broad user-centred approach to understand and support their customer's work behaviour. This would represent two development strategies for integrating products and services. One that builds upon the product and its technologies (left to right in Fig. 1) and the other that builds on the user and his/her activities (right to left in Fig. 1). Based on a study of 11 large capital equipment manufacturers Oliva and Kallenberg [35] suggest a deliberate transition from products to services involving defined steps. Although the companies in both cases offer a range of services covering the span depicted in Fig. 1, no structured progress for offering services was found. This may possibly be due to the fact that currently neither Danfoss nor Steelcase have clearly formulated business strategies that leverage service-orientation. Both companies consider services in their development, but without an integrated approach to the product-oriented and customer-oriented methods. The technology and product development organisations generally operate without much connection to the marketing and sales organisations.

When offering integrated solutions and services both companies have managed to achieve a closer and more intimate relationship with their customers, but at the same time were cautious that this move down the value chain was not perceived as a threat by existing actors on the market. This was done by establishing customer-oriented organisations independent of their own product-oriented business units. This separation of product and service development allows both companies to offer customised integrated solutions, but requires more effort in terms of securing feedback loops from service to product design. Individuals from both companies express how different the product-oriented and service-oriented organisations are in terms of business motivation, culture and language, which makes it challenging to communicate and collaborate [36].

\section{CONCLUSION}

There is an increasing interest in PSS design and how manufacturing firms are moving to more service-oriented approaches. Present literature provides a number of approaches to integrating products and services but often due to the multiple meanings of 'service' it is not clear which strategy for developing services should be applied. This paper has presented an overview of service-oriented development strategies found in literature and what types of services they relate to.

To challenge the literature review two case studies of manufacturing companies were presented to better understand the industrial context of developing services. Both companies developed and provided integrated solutions and services to deliver added value and achieve a closer relationship to their customers, but had to establish independent customer-oriented organisations so that they did not compromise existing business and actors on the market. The organisational separation of product-oriented and service-oriented development activities is a challenge for the sharing of design relevant information and does not seem to allow companies to take advantage of the potential integration benefits. There seems to be a gap in the systematic methods offered in literature and the current practices in manufacturing firms offering services. Given that only two case studies were offered of manufacturing companies, it is not possible to speculate whether the integration of development activities is an issue for other manufacturing firms following the same path. It still remains unclear whether the current span of service-oriented development strategies offered in literature sufficiently equips manufacturing companies to systematically design and develop PSS or whether other approaches need to be developed. 


\section{REFERENCES}

[1] Baines, T. S., Lightfoot, H. W., Evans, S., Neely, A., Greenough, R., Peppard, J., Roy, R., Shehab, E., Braganza, A., Tiwari, A., Alcock, J. R., Angus, J. P., Basti, M., Cousens, A., Irving, P. et al., 2007, Stateof-the-art in product-service systems, Institution of Mechanical Engineers, Part B: Journal of Engineering Manufacture, vol. 221, no. 10: 15431552.

[2] Davies, A., Brady, T., Hobday, M., 2007, Organizing for solutions: Systems seller vs. systems integrator, Industrial Marketing Management, vol. 36, no. 2: 183-193.

[3] Tukker, A., Tischner, U. (eds.), 2006, New Business for Old Europe. Product-Service Development, Competitiveness and Sustainability. Greenleaf Publishing, Sheffield.

[4] Mont, O., 2004, Product-service systems: Panacea or myth?, The International Institute for Industrial Environmental Economics. Lund, Lund University. $\mathrm{PhD}$ dissertation.

[5] Brännström, O., Elfström, B-O., Thompson, G., 2001, Functional products create new demands on product development organisations, Int. Conf. On Engineering Design (ICED01), Glasgow, 21-23 August.

[6] Tomiyama T., 2005, A Design Methodology of Services, Int. Conf. On Engineering Design (ICED05), Melbourne, 15-18 August.

[7] White A.L., Sloughton M., Feng L., 1999, Servicizing: The Quiet Transition to Extended Product Responsibility, Tellus Institute, Boston.

[8] Vandermerwe, S., Rada, J., 1988, Servitization of Business: Adding Value by Adding Services, European Management Journal, vol. 6, no. 4: 315324.

[9] Tan, A.R., McAloone, T. C., Andreasen, M.M., 2006, What Happens to Integrated Product Development Models with Product/Service-System Approaches?, the 6th Integrated Product Development Workshop, IPD 2006, Magdeburg, Germany, 18-20 October.

[10] Kuo, T.-C., S. H. Huang, Zhang, H.-C., 2001, Design for manufacture and design for ' $X$ ': concepts, applications, and perspectives. Computers and Industrial Engineering, vol. 41, no. 3: 241-260.

[11] Hubka,V., Eder, W.E., 1988, Theory of Technical Systems, Springer-Verlag, Berlin, Germany.

[12] Meerkamm, H., 1994, Design for X - a core area of design methodology, Journal of Engineering Design, vol. 5, no. 2: 145-63.

[13] Moss, M.A., 1985, Design for Minimal Maintenance Expense, Marcel Dekker, New York and Basel.

[14] Tjiparuro, Z., Thompson, G., 2004, Review of maintainability design principles and their application to conceptual design, Institution of Mechanical Engineers, Part E: Journal of Process Mechanical Engineering, vol. 218, no. 2 : 103-113.

[15] Blanchard, B.S., Fabrycky, W. J., 1998, Systems Engineering and Analysis, Prentice-Hall, NJ.

[16] Lee, J., 2003, Smart Products and Service Systems for e-Business Transformation, International Journal of Technology Management, vol. 26, no. 1: 45-52.

[17] Lynch, T., 1995, Design's next step: Serviceability, Design News, vol. 51, no. 12: 78.

[18] Editorial, 1994, Designing for the Future, World Class Design to Manufacture, MCB University Press, vol. 1 , no. $4: 46-48$.
[19] Lele, M. M., 1997, After-sales service - necessary evil or strategic opportunity?, Managing Service Quality, vol. 7, no. 3: 141-145.

[20] Takata, S., Kirnura, F., van Houten, F.J.A.M, Westkamper, E., Shpitalni, M., Ceglarek, D., Lee, J., 2004, Maintenance: Changing Role in Life Cycle Management, CIRP Annals - Manufacturing Technology, vol. 53, no.2: 643-655.

[21] Goffin, K., 2000, Design for supportability: essential component of new product development, Research Technology Management, vol. 43, no.2: 40-47.

[22] Harrison, A., 2006, Design for Service Harmonising Product Design with a Services Strategy, ASME Turbo Expo 2006: Power for Land, Sea and Air (GT2006), Barcelona, Spain.

[23] Andreasen, M.M., Hein, L., Kirkegård, L., Sant, K., 1989, The Development Task - basis for innovation (Udviklingsfunktionen - basis for fornyelse), Jernets Arbejdsgiverforening, Copenhagen, Denmark.

[24] Shostack, G.L., 1982, How to Design a Service, European Journal of Marketing, vol.16, no.1: 49-63.

[25] Edvardsson, B., Gustafsson, A., Roos, I., 2005, Service portraits in service research: a critical review, International Journal of Service Industry Management, vol.16, no. 1: 107-121.

[26] Grönroos, C., 2007, Service Management and Marketing: Customer Management in Service Competition, John Wiley \& Sons.

[27] Vargo, S. L., Lusch, R. F., 2004, Evolving to a New Dominant Logic for Marketing, Journal of Marketing, vol.68, no. 1: 1-17.

[28] Vandermerwe, S., 2000, How Increasing Value to Customers Improves Business Results, MIT Sloan Management Review, vol. 42, no. 1: 27-37.

[29] Moritz, S., 2005, Service Design - Practical access to an evolving field, Köln International School of Design.

[30] Shimomura, Y., Watanabe, K., Arai, T., Sakao, T., Tomiyama, T., 2003, A proposal for service modeling, 3rd Int. Symp. on Environmentally Conscious Design and Inverse Manufacturing EcoDesign'03, Tokyo, Japan.

[31] Yang, X., Moore, P.R., Chi-Biu Wong, C-B, JunSheng Pu, J-S., Chong, S. K., 2007, Product lifecycle information acquisition and management for consumer products, Industrial Management + Data Systems, vol. 107, no. 7: 936-953.

[32] Andreasen, M.M., Hein, L. 1987, Integrated Product Development, IFS Publications Ltd/Springer-Verlag.

[33] Engwall, M., 2003, The mystery with the unreasonable model: on development models, knowledge and control (Mysteriet med den orimliga modellen: Om utvecklingsmodeller, kunskap och kontrol), Nordiske Organisasjonsstudier, vol. 5, no. 4: 28-53.

[34] Manzini E., Collina L., Evans, S. (Eds), 2004, Solution oriented partnership, Cranfield, Cranfield University.

[35] Oliva R., Kallenberg, R., 2003, Managing transition from products to services, International Journal of Service Industry Management, vol. 14, no. 2: 160172.

[36] Mills, J., Neaga, E., Parry, G., Crute, V., 2008, Toward a framework to assist servitization strategy implementation, 19th Annual Conference of the Production and Operations Management Society (POMS), La Jolla, California, USA, 9-12 May. 